\title{
A systematic design approach for objectifying Building with Nature solutions
}

Mindert de Vries ${ }^{1,2,5}$, Mark van Koningsveld ${ }^{3,4,5}$,

Stefan Aarninkhof ${ }^{4,5}$, \& Huib de Vriend ${ }^{4,5}$

\author{
1. Deltares \\ 2. Van Hall Larenstein University of Applied Sciences \\ 3. Van Oord Dredging and Marine Contractors B.V. \\ 4. Delft University of Technology, Faculty of Civil Engineering and Geosciences \\ 5. EcoShape
}




\section{Abstract}

Hydraulic engineering infrastructure is supposed to keep functioning for many years and is likely to interfere with both the natural and the social environment at various scales. Due to its long life-cycle, hydraulic infrastructure is bound to face changing environmental conditions as well as changes in societal views on acceptable solutions. This implies that sustainability and adaptability are/ should be important attributes of the design, the development and operation of hydraulic engineering infrastructure. Sustainability and adaptability are central to the Building with Nature (BwN) approach. Although nature-based design philosophies, such as BwN, have found broad support, a key issue that inhibits a wider mainstream implementation is the lack of a method to objectify BwN concepts. With objectifying, we mean turning the implicit into an explicit engineerable 'object', on the one hand, and specifying clear design 'objectives', on the other. This paper proposes the "Frame of Reference" approach as a method to systematically transform BwN concepts into functionally specified engineering designs. It aids the rationalisation of BWN concepts and facilitates the transfer of crucial information between project development phases, which benefits the uptake, acceptance and eventually the successful realisation of BwN solutions. It includes an iterative approach that is well suited for assessing status changes of naturally dynamic living building blocks of BwN solutions. The applicability of the approach is shown for a case that has been realised in the Netherlands. Although the example is Dutch, the method, as such, is generically applicable.

\section{KEYWORDS}

Building with Nature, ecosystem services, frame of reference, objectification, design, solutions 


\section{Nature based design philosophies}

Present-day trends in society (urbanisation, growing global trade and energy demand, stakeholder emancipation, increasing environmental concern) and in the environment (loss of biodiversity, climate change, sea level rise, subsidence, etc.) put ever higher demands on the engineering of infrastructure. Mono-functional solutions designed without due consideration of the ambient system are no longer accepted. Sustainability, multi-functionality, and stakeholder involvement are required instead.

This trend equally applies to hydraulic engineering works and the associated water management system (Adger et al., 2005; Farber et al., 2006; Kamphuis, 2006; Van Koningsveld et al., 2008; Kabat et al., 2009). It triggers awareness that projects should be developed differently, multi-functional, adaptable and in line with environmental and stakeholder interests incorporated right from the start (McHarg, 1995; Mitsch and Jorgensen, 2004; Farber et al., 2006; Hallegatte, 2009; Misdorp, 2011).

Traditional approaches tend to focus on realising the primary functionality of the project and minimising or compensating the negative impacts (cf. Linde et al., 2013). Stepping beyond these reactive approaches, Building with Nature (BwN) aims to be proactive, utilising natural processes and providing opportunities for nature as an integral part of the infrastructure development process (Waterman, 2008; Van Koningsveld et al., 2010; De Vriend and Van Koningsveld, 2012; De Vriend et al., 2014, 2015; Laboyrie et al, 2018). Similar philosophies have emerged, such as 'Working with Nature' promoted by PIANC (PIANC, 2011) and 'Engineering with Nature' promoted by the US Army Corps of Engineers (Bridges et al., 2014).

Although the basic idea that engineering infrastructure should be integrated better with the surrounding natural and/or societal system has found broad support, the lack of a method to objectify BwN solutions inhibits a wider mainstream implementation. Such a method should turn the implicit into an explicit engineerable object, on the one hand, and specify clear design objectives, on the other.

Inherent natural variability and a limited understanding of ecosystem behaviour make it difficult to engineer natural components such that a set service level is achieved. Furthermore, perceptions of the extent to which one can rely on natural components, given their dynamic nature and inherent uncertainty, may differ implicitly between actors in an infrastructure development process (Van den Hoek et al., 2014). Objectification of such aspects supports a fair comparison of alternatives, thus improving the chances of $\mathrm{BwN}$-alternatives to become a mainstream solution. 
In this paper we demonstrate the importance of objectification as an enabler for the design and implementation of BwN solutions, while testing the Frame of Reference (FoR) approach (Van Koningsveld and Mulder, 2004; Laboyrie et al, 2018) as a means to do so. The general principles of the BwN philosophy and the steps to come to conceptual project designs are described first, followed by a description of the FoR approach, its application to a practical BwN case and the lessons learned. Although the case is Dutch, the approach is generally applicable.

\section{Building with Nature (BwN)}

\section{General principles}

BwN is about meeting society's infrastructural demands by starting from the functioning of the natural and societal systems in which the infrastructure is to be realised. The aim is not just to comply with these systems, but also to make the optimum use of them and at the same time create new opportunities. Doing so requires different ways of thinking, acting, and interacting (Waterman, 2008; De Vriend and Van Koningsveld, 2012; De Vriend et al., 2014, 2015).

Thinking. Thinking does not start from a certain design concept focusing on the primary function, but rather from the natural system, its dynamics, functions, and services, and from the vested interests of stakeholders. Within this context, one seeks optimal solutions for the desired infrastructural functionality.

Acting. The project development process requires different forms of acting because it is more collaborative and extends beyond the delivery of the engineering object. The natural components embedded in the project will take time to develop afterwards and one has to make sure they function as expected. Post-delivery monitoring and projections into the future are integral parts of the project. This also creates opportunities to learn from such projects than from ones that stop at the delivery of the engineering object.

Interacting. BwN project development is a matter of co-creation between experts from different disciplines, stakeholders (cf. Temmerman et al., 2013). This requires a different attitude of all parties involved and different ways of interaction, in interdisciplinary collaborative settings rather than each actor taking up his task and executing it in relative isolation. 


\section{Steps towards conceptual BwN designs}

Project development generally goes through a number of consecutive phases, often in an iterative process. One might distinguish 'Initiation', 'Planning and Design', 'Construction' and 'Operation and Maintenance', but other distinctions are equally suitable.

An important starting point for any development should be the environment in which a project is to be embedded. A key characteristic that distinguishes a BwN design from other integrated approaches is the proactive utilization and/or provision of ecosystem services (e.g. Costanza et al., 2017) as part of the engineering solution. The following five steps can be applied in each project development phase to develop BwN designs (De Vriend and Van Koningsveld, 2012; EcoShape, 2012; De Vriend et al., 2015):

1. Understand the ambient system beyond the primary objective (including ecosystem services, values and interests).

2. Proactively identify realistic alternatives that use and/or provide ecosystem services, involving experts, decision makers and other stakeholders.

3. Evaluate the qualities of each alternative, including natural and societal costs and benefits, and preselect an integral solution.

4. Fine-tune the selected solution, complying with practical restrictions and governance context.

5. Prepare the solution for implementation in the next project phase, making essential elements explicit to facilitate uptake in the next phase.

Fundamental to the above design steps is a thorough knowledge of how the natural system functions and a correct interpretation of the signals to be read from its behaviour. The latter may indicate in what direction the system is evolving, how to integrate a desired development and how to make use of the ecosystem services available. They may also provide an early warning of adverse developments or indicate an increased sensitivity to natural hazards. Investing in a better understanding of the natural system and its inherent variability does not only pay off in the realisation of the project, but also to the system's overall management (De Vries et al., 2020).

\section{Objectifying conceptual BwN designs with the Frame of}

\section{Reference approach}

\section{The "Frame of Reference" approach}

The Frame of Reference (FoR) approach (Van Koningsveld, 2003; Van Koningsveld et al., 2003; Van Koningsveld and Mulder, 2004) was developed 
to match specialist knowledge with end user needs by making the essential components of a decision problem explicit. In that way, the FoR approach streamlines discussions between different actors, following an interactive process to achieve ongoing refinement. To make the approach applicable in practice, Van Koningsveld and Mulder (2004) suggest the use of a 'basic FoR template' which contains a limited set of elements that appear to be systematically present in successfully implemented policies. Fundamental to this approach is the definition of clear objectives at strategic and operational levels, reflecting key elements of the policy strategy. For the operational phase, indicators are defined to verify whether or not the objectives are met. The operational phase requires specification of the following elements:

- the Quantitative State Concept (QSC),

- a benchmarking procedure,

- an intervention procedure, and

- an evaluation procedure.

These elements interact as indicated in Figure 1.

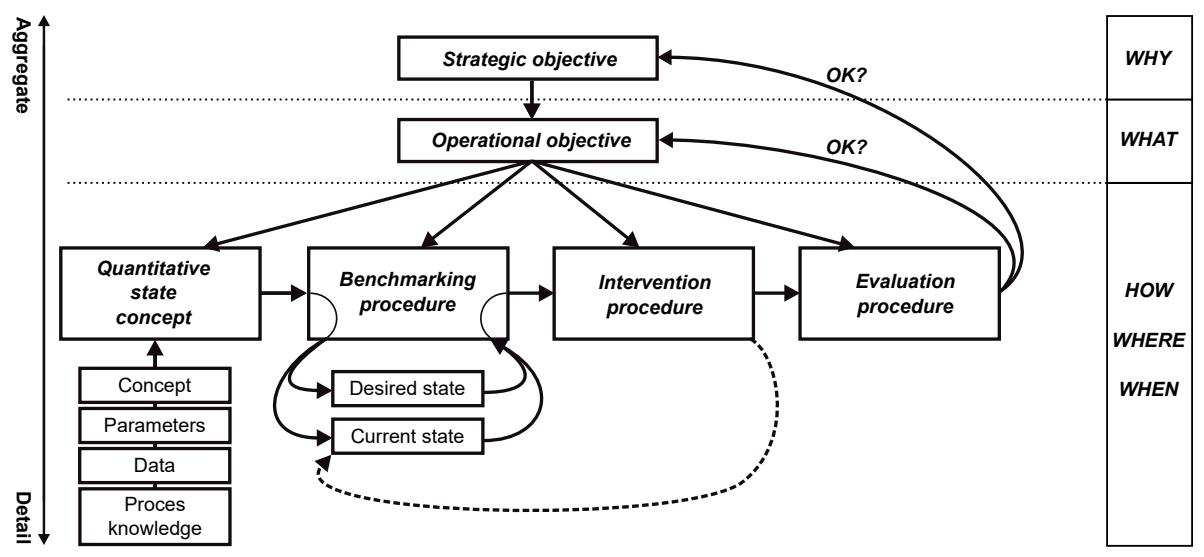

Figure 1. The 'basic Frame of Reference template' (modified from: Marchand, 2010, 2011)

It is important to identify, in a specific case, the envisaged authority responsible for the FoR as a whole, or elements thereof. The definition of elements may depend on the end user, so as to promote future uptake. Ideally, all elements of the 'basic FoR template' are made explicit in the end user-specialist interaction. Remaining 'white spots' represent information gaps for decision making and may become part of a knowledge agenda. 
The FoR approach has been applied to a variety of projects, bringing together people from different disciplines, nationalities and backgrounds with policy and decision makers. It has been used (implicitly) since the 1990's in the Netherlands for the successful development and implementation of an integrated local - regional scale resolving coastal sediment management policy (Van Koningsveld and Mulder, 2004; Mulder et al., 2007; Van Koningsveld and Lescinski, 2007; Mulder et al., 2011). It was used in combination with the Argus video observation system in beach recreation planning (Jiménez et al., 2011), management of dynamic navigation channels (Medina et al., 2007) and coastline management problems (Kroon et al., 2007). It was used to define management policies for the Danube delta coast (Stanica et al., 2011), for North-West Mediterranean urban beaches (Jiménez et al., 2011), for a shingle beach in Pevensy (UK) (Sutherland and Thomas, 2011) and for Inch beach in South West Ireland (Gault et al., 2011). Ciavola et al. (2011a, b) applied it to find practical applications of real time flood predictions, that included storm induced morphology change, for coastal zone managers. Garel et al. (2014) used it to develop environmental monitoring schemes for offshore renewable energy projects. Laboyrie et al. (2018) propose the FoR approach as a tool for project assessment.

\section{Application to BwN}

Using the FoR as a rationalisation method for BwN projects, conceptual designs that emerge from the aforementioned five steps need to be broken down into clearly separated, yet interacting components, which we will call design elements. Next to a strategic objective, clearly defined operational objectives of each of these elements are fundamental. The performance of each design element can be assessed using the template of Figure 1. Once each element meets its operational objectives (the desired state), the design as a whole, consisting of the interacting elements, has to be checked against the strategic objectives. Apart from this, fitting the solution into the local governance context is crucial to move it forward to practical implementation.

In summary, this leads to the following rationalisation steps:

1. Define the strategic objective and break down the solution concept into design elements;

2. Specify operational objectives, boundary conditions, per $\neg$ formance requirements and limit levels for each element;

3. Elaborate on the elements using the Quantitative State Concept;

4. Check if each element achieves its operational objective(s);

5. Check if the interacting elements collectively achieve the strategic objective, and

6. Check how the designed project fits into the local governance context. 
This objectification process can be used in each project phase, as well as for the transfer of crucial information between phases. The next section illustrates this with a practical example.

\section{The Fort Steurgat case}

Part of the 'Room for the River' program (Ministry of Transport Public Works and Water Management et al., 2006) was to reinstate the Noordwaard polder as a floodwater outlet, in order to cope with the increased river flow defined in the update of the regulatory design level river water discharges in the Dutch Rhine branches after the floods of 1993 and 1995. This meant that the village of Werkendam, including the historical Fort Steurgat, needed new flood protection infrastructure. Local stakeholders were against a high dike. Therefore, a lower dike design with a wave-attenuating foreshore was chosen (figure 2).

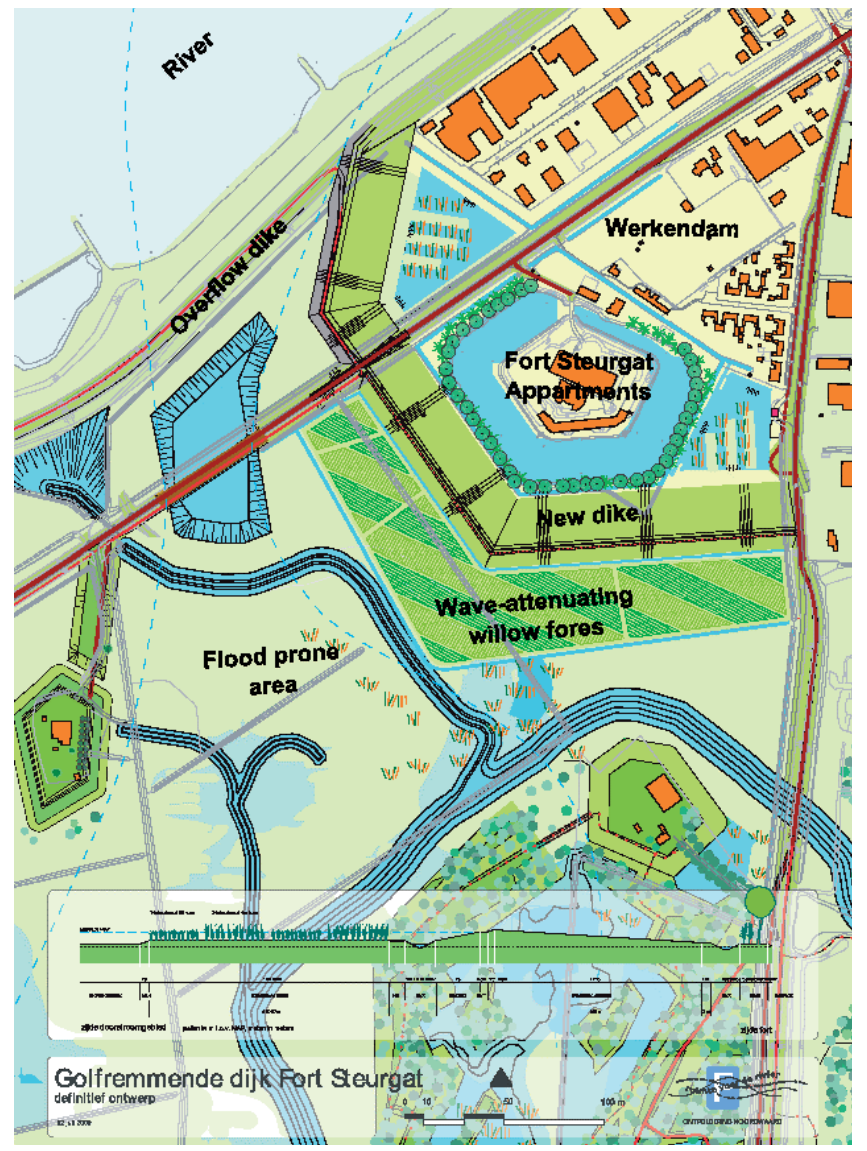

Figure 2. Final design of Forest-Dike Noordwaard (modified from: De Vries and Dekker, 2009). 
The foreshore is $600 \mathrm{~m}$ long and has a width of $60 \mathrm{~m}$ near the edges up to $100 \mathrm{~m}$ near the bend. It has a bank height of $0.8 \mathrm{~m}$ above the original polder level in order to keep the roots of nearby vegetation (willow trees) from permanently submerged in water-saturated soil.

The willow species Salix alba and Salix viminalis were chosen because of their ability to cope with long inundation periods, their resistance against extreme storms and their ability to grow in clay soil. Trees are maintained by cutting, resulting in a stub from which the branches re-grow. This form of willow forest maintenance has been a common practice for many centuries in this area. The maintenance strategy involves zoning and alternate cutting to ensure sufficient wave dissipation capacity at all times. The willow forest and foreshore can be adapted to cope with changing boundary conditions if need be.

\section{Rationalising a Building with Nature concept using the FoR}

\section{approach}

To demonstrate the applicability of FoR to the rationalisation of BwN projects, we apply the iterative six-step procedure to the case of Fort Steurgat in the next chapters. In Figure 3, the FoR structure is illustrated and numbers shown indicate the chapters where steps are elaborated.

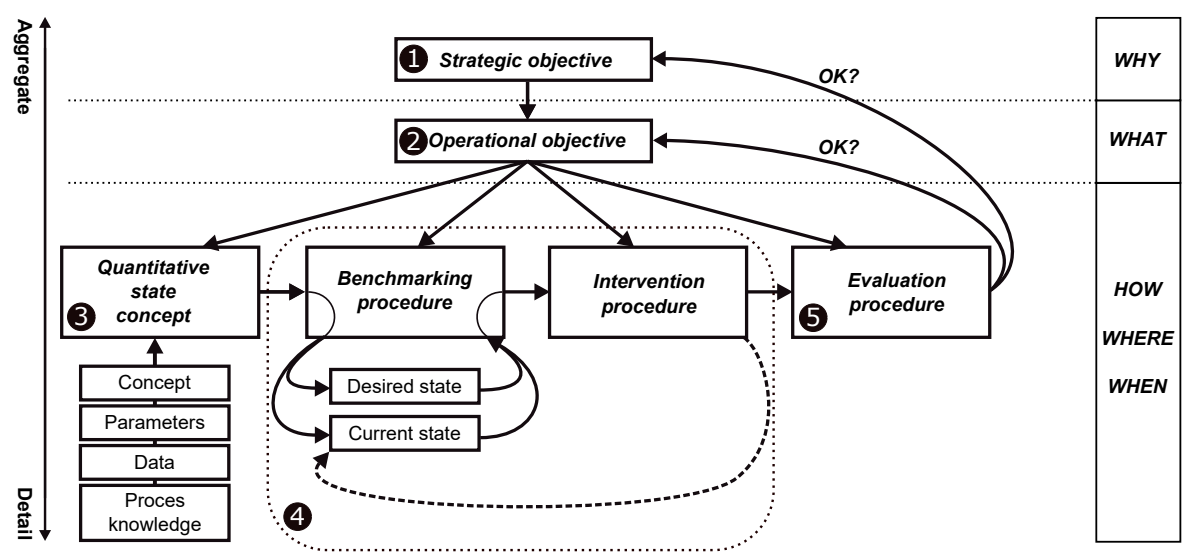

Figure 3. The five steps of the Frame of Reference provide an iterative link between detail quantification of services delivered (how, where and when) and aggregate level formulation of objectives (why and what) within an iterative process. 
Step 1: Define the strategic objective and break down the solution concept into design elements (figure 3 ).

The strategic objective of the Fort Steurgat flood protection system was to design, construct and maintain a hybrid flood protection solution that complies with legally required safety levels while delivering additional nature and landscape value, including an as low as possible, grass-covered dike, less construction costs and more stakeholder satisfaction.

We adopt this strategic objective and the final design outlined in Figure 2 as a starting point to demonstrate the objectification process.

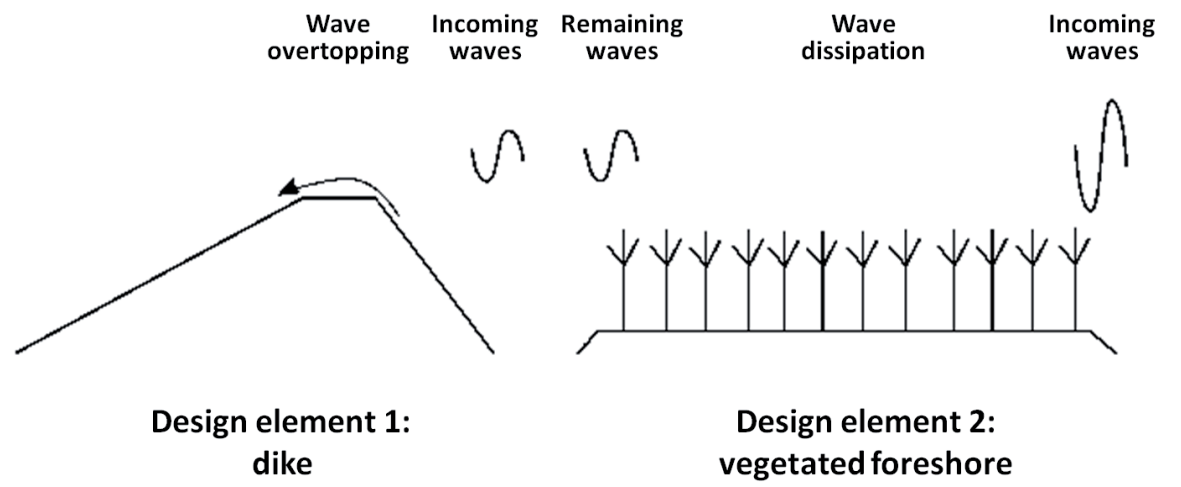

Figure 4. Visualisation of design elements for the foreshore-dike (hybrid) flood defence Noordwaard.

For any dike, geotechnical stability and crest height are key requirements. The strategic objective of having a low grass-covered dike indicates that overtopping will become the main design criterion and that geotechnical stability in that case requires special attention. Two elements of the conceptual design play a key role in achieving the strategic objective, viz. the dike protecting Fort Steurgat (slope, height, and dike cover) and the vegetated foreshore (width, height, and vegetation cover), see Figure 4.

\section{Step 2: Specify operational objectives, boundary conditions and}

performance indicators for each element.

The next step in the process is the specification of operational objectives per design element. (see Figure 3). The Fort Steurgat flood protection system, as a whole, had the operational objective to provide protection against flood and wave conditions with a probability of occurrence of $1 / 2000$ per year, as required by Dutch legislation (Ministerie van Verkeer en Waterstaat 2006, 2007) at the time.

Both design elements play a role in achieving this objective. Element 1 (dike) should be able to withstand the 1/2000 per year water level and associated wave overtopping. Element 2 (foreshore) should reduce the wave height 
at the toe of the dike to an acceptable level. Clearly, the two are interacting, the wave-attenuation that the foreshore needs to provide depends on the wave height the dike can manage, given its crest height, slope, and cover. The ideal combination is to be determined iteratively in a dynamic optimisation process. In the remainder of this analysis, the water level was fixed at the design level and was therefore not an operational objective that could be tuned in the design. Focussing on overtopping, this led to the following operational objective for the dike:

"To achieve sufficient dike height and wave dissipation on the dike slope to reduce overtopping under design conditions to maximum $2 \mathrm{l} / \mathrm{s} / \mathrm{m}$ "

Design parameters are crest height, inner and outer slope, and dike cover. To meet stakeholder wishes, a very mild inner slope was chosen. This allowed choosing the relatively high overtopping discharge of $2 \mathrm{l} / \mathrm{s} / \mathrm{m}$. Iterations between dike and foreshore design ultimately led to the following operational objective for the foreshore:

"To achieve sufficient attenuation of the incoming waves to have a maximum significant wave height of $0.5 \mathrm{~m}$ at the toe of the dike"

Design parameters are the height and width of the foreshore, in combination with height, width, and density of the vegetation.

Step 3: Elaborate the design elements using the Quantitative State Concept

To make the step from objectives to technical design, it is necessary to capture the essence of the operational objectives in a Quantitative State Concept (QSC) (see Figure 3). The dike overtopping rates on a representative dike profile or cross section are legally required to be calculated with PC-OVERTOPPING (available via www.overtopping-manual.com). This tool therefore serves as a quantification tool in the QSC for Element 1.

For the foreshore, wave attenuation was quantified with the spectral wave model SWAN (Booij et al., 1999), extended with algorithms for wave attenuation by vegetation (Suzuki et al., 2012). De Oude et al. (2010) used this model as a QSC-tool for the design of the willow forest in front of the dike, yielding requirements for stem diameter, drag, and density. Once the QSCs have been specified it is possible to optimise the design in an iterative process, the benchmarking procedure (see Figure 3):

- fix boundary conditions and design parameters for the element;

- create a first design of the element;

- apply the QSCs to quantify services delivered by the element design;

- compare delivered services with required services (the benchmark);

- if insufficient, adapt the element design; if sufficient move to next step. 
If it is not possible to iteratively deliver a technical design that achieves the benchmark, this may trigger a revision of choices made in the previous steps. The problem may arise from poorly defined objectives and/or QSCs, but lacking knowledge, data or operational tools might also be the cause.

In the Fort Steurgat case, this process led to a dike crest height of $4.25 \mathrm{~m}$ above ordnance level (NAP) and an outer dike slope of 1:3. Such a slope with a closed grass cover on a $0.40 \mathrm{~m}$ clay layer will withstand waves with $\mathrm{Hs}=0.5$ $\mathrm{m}$ for at least 20 hours (Van der Meer et al., 2012). For the foreshore it led to a required tree height exceeding the designed water level and a minimum vegetation factor (defined as the number of stems per $\mathrm{m}^{2} \mathrm{x}$ stem diameter $\mathrm{x}$ drag coefficient) of $2.4 \mathrm{~m}-1$. Note that this factor varies between seasons and with the state of maintenance.

\section{Step 4: Check if each design element achieves its operational objective(s)}

The final steps in the objectification process are used to evaluate the resulting design (see Figure 3). The evaluation should address two levels, viz. the operational objective(s) for each design element and the strategic objective for the design as a whole. Also, how it fits within the local governance context should be checked.

The evaluation procedure at the level of the design element checks if the resulting design meets its operational objective, i.e. achieves its specified desired state. In the Planning and Design phase, this may seem like a trivial step, but its true added value emerges when a design is actually constructed, operated and maintained. Especially when natural elements are integrated in the design, its effectiveness should be checked regularly to account for inherent dynamics and unforeseen behaviour. This is caused by the inherent variability of such an element as it develops through time, reacting to its environmental and anthropogenic surroundings.

\section{Step 5: Check if the elements collectively achieve the strategic objective}

Evaluation against the strategic objective usually provides the strongest triggers for redesign. In the present case, a logical question would be if the feeling of nature is achieved by the willow forest. It is good to keep in mind here that the local stakeholders' initial resistance was fuelled by the desire to prevent an unattractive and 'unnatural' high dike in front of their houses. Contributing to a more natural solution that would fit better into the local context was a main driver for the present design

Step 6: Check how the final solution fits into the local governance context

An important final step is a reflection on how the proposed solution fits into the local governance context. This includes identifying the authority responsible (hence the owner of the benefits), but also problems that may 
ensue from new infrastructure. It also encompasses checking whether the proposed solution is financially viable and compliant with existing laws and regulations. In this case, the grass-covered clay dike design, using clay from the foreshore, with optimal design of the willow forest for future mechanical maintenance, resulted in a lower overall cost for the dike section compared to the classical design that included a dike cover consisting of concrete blocks.

\section{Applicability of the FoR approach across different project}

\section{phases}

The analysis in the previous subsections can be regarded as the outcome of the Initiation and Planning and Design phases. Continuously reviewing the resulting FoR when moving through the other project development phases is an effective way to prevent reduced effectiveness of the final solution or even failure of the solution to deliver the intended outcome.

Unanticipated practical decisions made during the construction phase, for instance, can influence the effectiveness of the overall scheme. In the Fort Steurgat case, the FoR from the Planning and Design phase specifies the height of the foreshore and type and density of vegetation to be planted thereon. The exact type of material to heighten the foreshore may not have been specified, the types of vegetation to be used may not be readily available, available equipment to profile the foreshore may not deliver the anticipated accuracy, the moment when a proposed ecosystem service needs to be delivered may not have been specified, tree growth could be slower or less dense than expected, etcetera. Anything left (un)intentionally implicit introduces the probability that further choices will inevitably reduce the effectiveness of the overall solution. Easy access to the project's objectives and insight in how the proposed solution intends to address these objectives helps to make decisions as much as possible in line with the project's original intentions.

Similar considerations apply to the operation and maintenance phase. Dynamic behaviour is inherent to nature-based solutions. This means that regular assessments of the functionality of the solution are required. In the Fort Steurgat case, dynamic issues to consider include timing when the solution should start to deliver its full wave dissipating service and the effect that seasonality, tree mortality, disease, regrowth, succession and maintenance might have on the project's performance (also see Borsje et al., 2011).

A complicating issue, especially for projects designed for rare events like extreme floods, is that it may not be possible to test the functionality under design conditions. In the Fort Steurgat case, for instance, the design relies on SWAN and PC-Overtopping, but given the natural conditions and the $1 / 2000$ 
per year probability of occurrence within the design conditions, it is not very likely that wave dissipation and overtopping can be measured in the field. To overcome this issue, measured stem diameter, stem drag and stem density on the foreshore are used as a proxy.

\section{Lessons learned from application of the FoR to BwN}

Based on various applications of the FoR template, some recurring issues have arisen that may serve as lessons learned. When applying the 'basic FoR template', one can avoid common pitfalls by considering the following lessons learned:

(1) Check whether each element is filled with the kind of information prescribed in the 'basic FoR template', i.e.

- Try to avoid formulating objectives as actions. In the Noordwaard case, the objective is not to build a dike with a vegetated foreshore, but to have a safe situation that is acceptable to the stakeholders.

- Check whether the operational objectives are logically connected to the strategic objective and provide sufficient handles to further elaborate the design.

- A QSC should not be formulated as an action, it should rather be linked with models or measured data.

- Think ahead, who is the actor that you envisage as the 'owner' of the objectives, as well as the underlying decision formula.

(2) Check the logical coherence of objectives, state concepts and interventions

- For each step, think about the links with previous and following steps.

- Approach the FoR from different angles (e.g. demand driven, starting from the objectives; or technology driven, starting from the QSC or the intervention). It may provide new insights into the overall coherence.

- In the benchmarking step, check whether the proposed intervention method in fact eliminates the problem.

- Consider whether the suggested intervention matches with the actor who 'owns' the objectives and with stakeholder interests.

(3) Take your time to define the desired state in the benchmarking step

- Try to support benchmarks with scientific data. Often, literature is available, e.g. what kind of dike overtopping discharges have the potential to cause damage.

- Try to avoid subjective benchmarks. Desired states like 'sufficient naturalness', for a dune area, or 'historic atmosphere', for a beach front, can hard- 
ly be objectively assessed. This will present difficulties in trying to drive any concept or policy that is based on this FoR towards the next phase of implementation.

(4) Make sure in the evaluation step to reflect on the operational objective AND the strategic objective; this step provides the main triggers to modify the scheme.

With respect to the design and implementation case described in this paper, the FoR was used a posteriori to quantitatively clarify the chain of required services delivered by the natural elements of this BwN solution. Its structure defines a procedure that allows for quantification, benchmarking, intervention, and subsequent evaluation, a requirement for the long-term sustainability of the strategic and operational objectives of the design. Although the FoR was originally applied to more traditional designs, this paper shows that by its stepwise and iterative approach, it clearly provides a foundation for rationalising BwN designs that include natural elements. One valuable step forward is the further elaboration of the QSC's to better describe the natural elements regarding interactions with the ecosystem (this would require operational objectives that include the services delivered to the ecosystem as part of the design, not the case in the example). Better knowledge of natural variability can help to iteratively optimize the FoR QSC and benchmarking procedure. The used QSC's describe a static situation of a natural element and therefore can have led to an overdesign (by taking a too extreme worst-case performance as reference) or to an underestimation of risk of temporary underperformance (by not taking sufficient magnitude of variability of service on the long term into account). Benchmarking, intervention, and evaluation procedures of the FoR at least take care of the second issue raised and the application of the FoR could contribute data and management experience to further optimize the QSC and benchmarking of the vegetated foreshore design element.

The FoR approach has been helpful in identifying design elements, identifying, specifying, and documenting the QSC for the living building block of the solution. It has contributed ex ante to help setup an evaluation protocol and supporting monitoring activity in the operation and maintenance phase to establish the flood safety protection status of the dynamically developing implementation on the project site. It has become clear that the iterative and cyclic process of the FoR approach is well suited to maintaining operational objectives for a dynamically developing implementation. While it is clear that the specification of solely hydraulic operational objectives could have led to a complete 'grey' design, the strategic objective included the value of landscape and nature as important parameters. This could have produced a set of additional operational objectives. However, in the dike design process, those 
natural aspects have been not further evaluated, possibly leading to a underperforming implementation from a 'green' perspective. It is expected that the FoR approach will also be able to provide a complete process for those objectives. Both aspects have not been further researched yet.

\section{Conclusions}

This paper has shown the use of the FoR approach to rationally identify and structure physically explicit building blocks of BwN concepts. As such, it provides a valuable addition to the five steps for the design of $\mathrm{BwN}$ solutions. The six rationalisation steps enable the translation of abstract design concepts into tangible solutions that may be evaluated objectively. Being quantitative and explicit (for instance the ecosystem services the design aims to utilise and/or deliver) aids a fair comparison of BwN and more traditional alternatives, for example in a Cost-Benefit Analysis or an Environmental and Social Impact Analysis.

The FoR-based rationalisation approach should be regarded as an investment to enable an implementation of the BwN concept in practice. As a prescriptive tool, the FoR yields benefits in each of the project development phases. In the Initiation and Planning and Design phases. it helps to define objectives, indicators, reference states, mechanisms for mitigation, and evaluation procedures. In the Construction phase. it helps to steer unanticipated, but inevitable practical decisions to maintain conformity with the original design objectives. In the Operation and Maintenance phase. it helps to design monitoring programmes and maintenance measures that are closely tied to the original design objectives through the well-defined QSCs. As a descriptive tool, the FoR can consequently be used to evaluate existing designs, monitoring programmes and maintenance schemes.

As an integrative documenting tool, the FoR approach also improves the transfer of crucial information between project realisation phases. This helps to reduce the risk of failure or underperformance due to miscommunication or loss of important information. The FoR method was shown to work for a wide range of problems and disciplines. We believe that the example in this paper illustrates the FoR's applicability as a tool for objectifying BwN designs. The complex behaviour of natural elements results in a variability of services delivered. This issue is now safeguarded in the iterative benchmarking, intervention, and evaluation steps of the FoR. It is acknowledged by the authors that further research into better understanding this variability and the possibility of its management will help to fortify the QSC's and the benchmarking and intervention steps of the FoR when working on objectification of future BwN designs and solutions. 


\section{Acknowledgements}

Part of the work done for this paper is part of the BwN innovation programme, which was funded jointly by the partners of the EcoShape consortium, the Netherlands government, the European Fund for Regional Development, and the Municipality of Dordrecht. 
Adger, W. N., Hughes, T. P., Folke, C., Carpenter, S. R. \& Rockstrom, J. (2005). Social-Ecological Resilience to Coastal Disasters. Science,309(5737), 1036-1039. https://doi.org/10.1126/science.1112122

Booij, N., Ris, R. C., \& Holthuijsen, L. H. (1999). A third-generation wave model for coastal regions: 1. Model description and validation. Journal of Geophysical Research: Oceans, 104(C4), 7649-7666. https:// doi.org/10.1029/98jc02622

Borsje, B. W., van Wesenbeeck, B. K., Dekker, F., Paalvast, P., Bouma, T. J., van Katwijk, M. M., \& de Vries, M. B. (2011). How ecological engineering can serve in coastal protection. Ecological Engineering, 37(2), 113-122. https://doi.org/10.1016/j.ecoleng.2010.11.027

Bridges, T.S., Lillicrop, J., Wilson, J.R., Fredette, T.J., Suedel, B., Banks, C.J., \& Russo, E.J. (2014). “Engineering with nature" promotes triple-win outcomes. Terra et Aqua, 135(2), 17-23. http://www.iadc-dredging. $\mathrm{com} / \mathrm{ul} / \mathrm{cms} /$ terraetaqua/document/4/1/1/411/411/1/ article-engineering-with-nature-promotes-triple-win-outcomes-terra-et-aqua-135-2a.pdf

Ciavola, P., Ferreira, O., Haerens, P., Van Koningsveld, M., \& Armaroli, C. (2011). Storm impacts along European coastlines. Part 2: lessons learned from the MICORE project. Environmental Science \& Policy, 14(7), 924-933. https://doi.org/10.1016/j.envsci.2011.05.009

Ciavola, P., Ferreira, O., Haerens, P., Van Koningsveld, M., Armaroli, C., \& Lequeux, Q. (2011). Storm impacts along European coastlines. Part 1: The joint effort of the MICORE and ConHaz Projects. Environmental Science \& Policy, 14(7), 912-923. https://doi.org/10.1016/j.envsci.2011.05.011

Costanza, R., de Groot, R., Braat, L., Kubiszewski, I., Fioramonti, L., Sutton, P., Farber, S., \& Grasso, M. (2017). Twenty years of ecosystem services: How far have we come and how far do we still need to go? Ecosystem Services, 28, 1-16. https://doi.org/10.1016/j.ecoser.2017.09.008

de Oude, R., Augustijn, D.C.M., Wijnberg, K.M., Dekker, F., De Vries, M.B., \& Suzuki, T. (2010). Bioengineering in front of a river dike: wave attenuation by vegetation. In G.C. Christodoulou \& A.I. Stamou (Eds.), Proceedings of the 6th International Symposium on Environmental Hydraulics, vol. 1. Athens, Greece, 23-25 June 2010 (pp. 253-258).CRC Press

de Vriend, H.J., \& Van Koningsveld, M., (2012). Building with Nature. Thinking, acting and interacting differently. EcoShape. http://ecoshape. nl/files/paginas/ECOSHAPE_BWN_WEB.pdf

de Vriend, H. J., van Koningsveld, M., Aarninkhof, S. G. J., de Vries, M. B., \& Baptist, M. J. (2015). Sustainable hydraulic engineering through building with nature. Journal of Hydro-Environment Research, 9(2), 159-171. https://doi.org/10.1016/j.jher.2014.06.004

de Vriend, H., van Koningsveld, M., \& Aarninkhof, S. (2014). 'Building with nature': the new Dutch approach to coastal and river works. Proceedings of the Institution of Civil Engineers - Civil Engineering, 167(1), 1824. https://doi.org/10.1680/cien.13.00003

de Vries, M.B., \& Dekker, F. (2009). Ontwerp groene golfremmende dijk Fort Steurgat bij Werkendam. Verkennende studie [technical report]. Deltares. https://www.deltares.nl/app/uploads/2015/07/Golfremmende-dijk-Noordwaard-rapport.pdf 
de Vries, M.B., van Koningsveld, M., Aarninkhof, S.G.J. \& de Vriend, H.J., 2020. Objectifying Building with Nature strategies: towards scale-resolving policies. In: Building with Nature perspectives - Cross-disciplinary BwN approaches in coastal regions. Research in Urbanism Series, 7, 51-72. https://doi. org/10.47982/rius.7.128

EcoShape. (2012). The Building with Nature Design Guideline. https://www.ecoshape.org/nl/design-guidelines/

Farber, S., Costanza, R., Childers, D.L., Erickson, J., Gross, K., Grove, M., Hopkinson, C.S., Kahn, S., Pincetl, S., Troy, A., Warren, P., \& Wilson, M. (2006). Linking ecology and economics for ecosystem management. BioScience, 56(2), 121-133.

Garel, E., Rey, C. C., Ferreira, Ó., \& van Koningsveld, M. (2014). Applicability of the "Frame of Reference" approach for environmental monitoring of offshore renewable energy projects. Journal of Environmental Management, 141, 16-28. https://doi.org/10.1016/j.jenvman.2014.02.037

Gault, J., O'Hagan, A. M., Cummins, V., Murphy, J., \& Vial, T. (2011). Erosion management in Inch beach, South West Ireland. Ocean \& Coastal Management, 54(12), 930-942. https://doi.org/10.1016/j.ocecoaman.2011.05.005

Hallegatte, S. (2009). Strategies to adapt to an uncertain climate change. Global Environmental Change, 19(2), 240-247. https://doi.org/10.1016/j.gloenvcha.2008.12.003

Jiménez, J. A., Gracia, V., Valdemoro, H. I., Mendoza, E. T., \& Sánchez-Arcilla, A. (2011). Managing erosion-induced problems in NW Mediterranean urban beaches. Ocean \& Coastal Management, 54(12), 907-918. https://doi.org/10.1016/j.ocecoaman.2011.05.003

Kabat, P., Fresco, LO., Stive, MJF., Veerman, CP., van Alphen, JSL., Parmet, BWAH., Hazeleger, W., \& Katsman, CA. (2009). Dutch coast in transition. Nature Geoscience, 2(July), 450-452. https://doi.org/ doi:10.1038/ngeo572

Kamphuis, J. W. (2006). Coastal engineering-quo vadis? Coastal Engineering, 53(2-3), 133-140. https:// doi.org/10.1016/j.coastaleng.2005.10.003

Kroon, A., Davidson, M. A., Aarninkhof, S. G. J., Archetti, R., Armaroli, C., Gonzalez, M., Medri, S., Osorio, A., Aagaard, T., Holman, R. A., \& Spanhoff, R. (2007). Application of remote sensing video systems to coastline management problems. Coastal Engineering, 54(6-7), 493-505. https://doi.org/10.1016/j. coastaleng.2007.01.004

Laboyrie, H.P., van Koningsveld, M., Aarninkhof, S.G.J., van Parys, M., Lee, M., Jensen, A., Csiti, A., \& Kolman, R. (2018). Dredging for sustainable infrastructure. CEDA/IADC.

Linde, M., Attard, R., \& Wilson, C. (2013 ). Undervaluing positive impacts in the environmental impact assessment process. Coasts and Ports 2013: 21st Australasian Coastal and Ocean Engineering Conference and the 14th Australasian Port and Harbour Conference.

Marchand, M. (2010-May). Framework for coastal erosion management. Deliverable D7, Concepts and Science for Coastal Erosion. Conscience. http://www.conscience-eu.net/documents/deliverable07-framework-for-coastal-erosion-management.pdf 
Marchand, M., Sanchez-Arcilla, A., Ferreira, M., Gault, J., Jiménez, J. A., Markovic, M., Mulder, J., van Rijn, L., Stănică, A., Sulisz, W., \& Sutherland, J. (2011). Concepts and science for coastal erosion management An introduction to the Conscience framework. Ocean \& Coastal Management, 54(12), 859-866. https:// doi.org/10.1016/j.ocecoaman.2011.06.005

McHarg, I. L. (1995). Design with Nature (25th ed.). Wiley.

Medina, R., Marino-Tapia, I., Osorio, A., Davidson, M., \& Martin, F. L. (2007). Management of dynamic navigational channels using video techniques. Coastal Engineering, 54(6-7), 523-537. https://doi. org/10.1016/j.coastaleng.2007.01.008

Misdorp, R. (Ed.). (2011). Climate of coastal cooperation. European Coastal and Marine Union (EUCC). http://www.coastalcooperation.net

Mitsch, W. J., \& Jørgensen, S. E. (2003). Ecological Engineering and Ecosystem Restoration (2nd ed.). Wiley.

Ministerie van Verkeer en Waterstaat. (2007). Hydraulische Randvoorwaarden primaire waterkeringen; voor de derde toetsronde 2006-2011 [Hydraulic Boundary conditions for primary water defences; for the third evaluation 2006-2011]. https://puc.overheid.nl/rijkswaterstaat/doc/PUC_128421_31/

Ministry of Transport Public Works and Water Management, Ministry of Housing, Spatial Planning and the Environment and Ministry of Agriculture, Nature and Food Quality of the Netherlands. (2006). Spatial Planning Key Decision Room for the River. Approved decision 19 December 2006 [Technical Report]. Dutch Government.

Mulder, J. P. M., Hommes, S., \& Horstman, E. M. (2011). Implementation of coastal erosion management in the Netherlands. Ocean \& Coastal Management, 54(12), 888-897. https://doi.org/10.1016/j. ocecoaman.2011.06.009

Mulder, J. P. M., Nederbragt, G., Steetzel, H. J., van Koningsveld, M., \& Wang, Z. B. (2007). Different implementation scenarios for the large scale coastal policy of The Netherlands. Coastal Engineering 2006, 1705-1717. https://doi.org/10.1142/9789812709554_0144

Permanent International Association of Navigation Congresses (PIANC). (2011). PIANC Position Paper 'Working with Nature' [technical report]. http://www.pianc.org/downloads/envicom/ WwN\%20Final\%20 position\%20paper\%20January\%202011.pdf

Stănică, A., Dan, S., Jiménez, J. A., \& Ungureanu, G. V. (2011). Dealing with erosion along the Danube Delta coast. The CONSCIENCE experience towards a sustainable coastline management. Ocean \& Coastal Management, 54(12), 898-906. https://doi.org/10.1016/j.ocecoaman.2011.06.006

Sutherland, J., \& Thomas, I. (2011). The management of Pevensey shingle barrier. Ocean \& Coastal Management, 54(12), 919-929. https://doi.org/10.1016/j.ocecoaman.2011.07.004

Suzuki, T., Zijlema, M., Burger, B., Meijer, M. C., \& Narayan, S. (2012). Wave dissipation by vegetation with layer schematization in SWAN. Coastal Engineering, 59(1), 64-71. https://doi.org/10.1016/j.coastaleng.2011.07.006 
Temmerman, S., Meire, P., Bouma, T. J., Herman, P. M. J., Ysebaert, T., \& De Vriend, H. J. (2013). Ecosystem-based coastal defence in the face of global change. Nature, 504(7478), 79-83. https://doi. org/10.1038/nature12859

van den Hoek, R. E., Brugnach, M., Mulder, J. P. M., \& Hoekstra, A. Y. (2014). Analysing the cascades of uncertainty in flood defence projects: How "not knowing enough" is related to "knowing differently." Global Environmental Change, 24, 373-388. https://doi.org/10.1016/j.gloenvcha.2013.11.008

van der Meer, J., Verheij, H., Hoffmans, G., Paulissen, M., Steendam, G., \& van Hoven, A. (2012- May). Handreiking toetsen grasbekledingen op dijken (in Dutch) [technical report. Report Number 1206016-000]. Deltares. http://publications.deltares.nl/WeL1947.pdf

van Koningsveld, M. (2003). Matching specialist knowledge with end user needs. Bridging the gap between coastal science and coastal management [dissertation]. University of Twente, Enschede, The Netherlands.

van Koningsveld, M., Davidson, M. A., \& Huntley, D. A. (2005). Matching Science with Coastal Management Needs: The Search for Appropriate Coastal State Indicators. Journal of Coastal Research, 213, 399-411. https://doi.org/10.2112/03-0076.1

van Koningsveld, M., Davidson, M., Huntley, D., Medina, R., Aarninkhof, SGJ., Jiménez, JA., Ridgewell, J., \& de Kruif, A. (2007). A critical review of the CoastView project: recent and future developments in coastal management video systems. Coastal Engineering, 6-7(54), 567-576. https://doi.org/10.1016/j. coastaleng.2007.01.006

van Koningsveld, M., De Vries, M., Damsma, T., \& Hibma, A. (2010 - June 29 till July 1). Building with nature: The art of maximising system potential [paper presentation]. 45th Defra Flood and Coastal Management Conference, Telford, UK.

van Koningsveld, M., \& Lescinski, J. (2006). Decadal scale performance of coastal maintenance in the Netherlands. Shore and Beach, 75, 1, 20-36.

van Koningsveld, M., \& Mulder, J.P.M. (2004). Sustainable Coastal Policy Developments in the Netherlands. A Systematic Approach Revealed. Journal of Coastal Research,20(2), 375-385. https://doi.org/10. 2112/1551-5036(2004)020[0375:SCPDIT]2.0.CO;2

van Koningsveld, M., Stive, M.J.F., Mulder, J.P.M., de Vriend, H.J., Dunsbergen, D.W., \& Ruessink, B.G. (2003). Usefulness and Effectiveness of Coastal Research. A Matter of perception? Journal of Coastal Research, 19, 441-461.

van Koningsveld, M., Mulder, J. P. M., Stive, M. J. F., van der Valk, L., \& van der Weck, A. W. (2008). Living with Sea-Level Rise and Climate Change: A Case Study of the Netherlands. Journal of Coastal Research, 242, 367-379. https://doi.org/10.2112/07a-0010.1

Waterman, R.E. (2008). Integrated coastal policy via Building with Nature. Opmeer Drukkerij. 


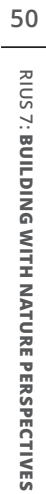

